Vol. 6, No. 1, 2019

https://doi.org/10.23939/eem2019.01.124

UDC 334.784

JEL Classification C51, D21, F15, L 10, L11

\author{
V. Kozyk \\ Lviv Polytechnic National University, Ukraine, PhD, Professor \\ National University Lviv Polytechnic \\ E-mail: Vasyl.V.Kozyk@lpnu.ua; v_kozyk@mail.ru
}

\author{
Kh. Zalutska \\ Lviv Polytechnic National University, Ukraine, PhD, Associate Professor \\ E-mail: khrystyna.y.solovii@lpnu.ua
}

V. Zalutsky

Lviv Polytechnic National University, Ukraine, PhD, Associate Professor

\title{
THE DEVELOPMENT OF SYNERGISTIC EFFECT IN THE DIVERSIFIED COMPANY
}

\begin{abstract}
The provision of effective activity of business entities requires a proper arrangement of work of all their structural subdivisions and their interaction, in particular, by making timely and informed strategic decisions. These decisions must include all areas and directions of activity, in particular, the relations with suppliers, consumers, contact audiences, market power in relation to main competitors, implementation of investment development programs, etc. Under such conditions the formation of a strategic set becomes of a particular relevance. Being a set of strategies of all levels, it will allow covering the maximum of each area of business entity activity. The article studies the possibility to make effective interconnections not only between the strategies of different levels but between the strategies of different business units of a diversified enterprise as well, which, taken together, will lead to the formation and use of synergistic effect by the enterprise at all levels of a strategic pyramid. Replacing a strategic set with a synergy strategic set for diversified enterprises, thus, will ensure their economic growth in a long-run period without the attraction of significant additional funds. Such development is caused by the formation and application of optimum (the most efficient) methods for enforcing the activity of one business units with others. The efficiency of a synergy strategic set is confirmed by a significant improvement of "Zakhar Berkut" ski resort activity during several
\end{abstract}

years after its implementation. Such results cannot be achieved in one year, since it takes a certain time to combine and allow for all possibilities of the enforcement of one business units with others.

Key words: strategy; diversified company; strategic set; synergy; relationship; strengthening; business unit.

\section{Problem statement}

The development of diversified enterprises is possible due to the formation and implementation of an effective business strategy. Its right choice will ensure that enterprises achieve sustainable long-term competitive advantages, the opportunities of their own capacity-building by reducing or avoiding the threats to the environment and eliminating the weaknesses of the enterprise by maximum and correct use of its strengths and external capabilities.

However, those companies that will develop and implement not one, but a complex of strategies - the so-called strategic set, will be more successful. By the strategic set of the enterprise should be understood a set of strategies for corporate, business and functional levels of management, which collectively form a pyramid of strategies. 


\section{The development of synergistic effect in the diversified company}

The need for the formation of the optimally validated strategic set of the enterprise is associated with a significant number of strategic alternatives at each level of the strategic pyramid. For example, a growth strategy can be achieved due to integration, diversification and concentration of the corporate activity, which in turn involves a set of strategic actions at the business level (focusing, differentiating of the efforts, etc.), which in turn require a specific investment, innovation, labor support, etc. And the more optimal and more thoroughly selected strategies of each level, the easier and more effective will be their implementation at each level of management separately, and for the enterprise as a whole. The development of a strategic set of the enterprise due to decomposition (scattering of the strategy of the corporate level) will allow to bring (to make it clear) to the immediate executors the strategic decisions and necessary actions for the implementation of business, functional and operational strategies as well.

As a strategic set of enterprises is a set of strategies at all levels of management, its development can be an effective tool for the establishment of only one-business enterprises. Diversified enterprises, which consist of a number of independent business units, must, besides the formation of strategies at different levels, also establish appropriate relationship both between the strategies of these levels and the strategies of specific business units, in order to provide with a stable position in the market. The existence of relationship between the strategies of the business units of the diversified enterprise (strategic business unit (SBU), business unit (BU)) will contribute to the formation of a synergistic effect [9], and the relationship between strategies of different levels of the strategic pyramid - the transfer of the synergistic effect to each of these levels, which will result in the establishment of a synergistic strategic set.

\section{Recent research and publications analysis}

The issues of the strategic set of enterprises and the synergistic effect are reflected in the works of such foreign and domestic scholars as H. Haken (Haken, 1985) [15], I. Ansoff ( Ansoff, 1987) [17], H. Itami (Itami, 1987) [18], A. Thompson and
A. Strickland (Thompson, Strickland, 1998) [14], James K. Van Horne (Van Horne, 2003) [3], T. Svitlychna [13], Zh. Poplavska [11], V. Holika [4], O. Revenko [12], A. Bohatyriova [1], Z. Shatska [16], I. P. Dobronravova [6], A. Dubrovyk [7] and others. In their works, the theoretical and practical aspects of the development processes and application by enterprises of strategic set and synergistic effect are summarized. However, beyond the attention of the research carried out is the issue of the possibility of combining them into a whole one and to get the concept of "synergistic strategic set", which, taking into account the advantages of both, would eliminate the shortcomings of each other. This requires a deeper and more substantial study of the synergistic strategic set issue in the direction of delineating the concepts of "strategic set of enterprise" and "synergistic strategic set of enterprise" with the outline of specific features (characteristics) of each of them and indicating ways of manifestation of the synergistic effect specifically at each level of management, in the formation of synergistic strategic set and at the corporate level when forming a strategic set of enterprises.

The purpose of the article is to develop a synergistic strategic set of a diversified company with features (characteristics) extraction of the synergistic effect on each level of the strategic pyramid, and to determine the effectiveness of its implementation at the example of Zakhar Berkut Ski Resort.

The methods of comparison, systematization and generalization in determining the essential features of the concept "synergy strategic set of the enterprise" were used in the article, as well as the method of portfolio analysis (matrix of the Boston consulting group) to determine the position of ski resort "Zakhar Berkut" and its business units in the market in different periods of the activity, which allowed to visualize the effectiveness of the generated synergy strategic set and determine the directions of further development of business units of the resort.

\section{The main findings of the research}

For a diversified company, the components of both a strategic set and a synergistic strategic set 


\section{Kozyk, Kh. Zalutska, V. Zalutsky}

are the strategies for corporate, business, functional and operational levels. The relationship between the strategies of these levels and the results obtained from their implementation are different.

The development of a strategic set is carried out by choosing the strategies at different levels and establishing appropriate relationship between them. At the same time, business units (BU) operate independently to achieve the proper result, and the relationship between business unit strategies is possible only at the business level in the case of application of the synergy strategy at the corporate level. In this case, the synergistic effect is formed as a result of strengthening the activity of some business units by the others within the framework of the established corporate strategy.

In a synergistic strategic set there is the relationship between strategies of different levels of the hierarchy and between strategies (business, functional and operational strategies) of different BU, which allows us to determine which characteristics and which business units are most effected by consumers in different situations, and to take the right strategic decisions on time that will provide the company with profits in the following years without increased costs. In this case, the synergistic effect on the functional level is manifested in the relationship between the individual functional strategies within the specific direction of the activity of a particular business unit; on the business level - in the relationship between functional strategies of different areas within a single business unit; at the corporate level - in the relationship between the competitive (business) strategies of business units.

That is, in the development process of :

! the strategic set - one should take into account that for a level below the organizational hierarchy, the top-level strategy becomes the goal, although for a higher level it was a means;

! a synergistic strategic set - not only the top-level strategy, but also business and functional strategies of other business units, mainly SBU, can be transformed into a goal.

The effectiveness of the formation and use of a synergistic strategic set in the activities of diversified enterprises is confirmed by the results of its implementation by Zakhar Berkut Ski Resort [2] (Table 1), which has undergone three stages of development since its foundation: Stage I. without the formation and implementation of strategies; Stage II. with the formation of a strategic set; Stage III. with the formation of a synergistic strategic set. At the first stage of its development, Zahar Berkut Ski Resort operated as one enterprise, which consisted of several units: a hotel; a restaurant; a cableway; two bar lifts.

Table 1

Business results of Zakhar Berkut Ski Resort

\begin{tabular}{|l|c|c|c|}
\hline \multirow{2}{*}{\multicolumn{1}{|c|}{ Indicators }} & \multicolumn{2}{|c|}{ Business results of Zahar Berkut Ski Resort, thsd. UAH } \\
\cline { 2 - 4 } & $\begin{array}{c}\text { before strategy } \\
\text { implementation }\end{array}$ & $\begin{array}{c}\text { having implemented a } \\
\text { strategic set }\end{array}$ & $\begin{array}{c}\text { having implemented } \\
\text { a synergistic strategic } \\
\text { set }\end{array}$ \\
\hline Operating expenses & 3612.742 & 8101.08 & 9010.96 \\
\hline $\begin{array}{l}\text { Revenue from the sale of tourist resort } \\
\text { services, including: }\end{array}$ & 4852.105 & 13635.05 & 25916.85 \\
\hline $\begin{array}{l}\text { Revenue from the sports and tourist } \\
\text { complex services }\end{array}$ & 2991.805 & 7394.156 & 11691.234 \\
\hline $\begin{array}{l}\text { Revenue from the hotel complex } \\
\text { services }\end{array}$ & 1288.235 & 4272.404 & 9773.426 \\
\hline Revenue from the catering services & 572.065 & 1296.12 & 2930.37 \\
\hline $\begin{array}{l}\text { Revenue from the services of the } \\
\text { transport complex }\end{array}$ & - & 672.37 & 1521.82 \\
\hline Profit after tax & 323.01 & 2446.095 & 9439.811 \\
\hline
\end{tabular}

Source: business results are calculated by the author on the basis of the data collected in the company 


\section{The development of synergistic effect in the diversified company}

Beginning from 2009, Zahar Berkut Ski Resort was first considered as a diversified enterprise divided into strategic business units "hotel complex", "sports and tourist complex", "catering complex", "transport complex" [8]. This period of the ski resort activity is characterized by the diversification of services - the emergence of new types; the expansion of the range of existing ones. For effective development, consolidation of stable positions in the market and obtaining strong long-term competitive advantages, Zahar Berkut Ski Resort in this period, implemented a strategic set consisting of: at the corporate level, the growth strategy; at the business level - strategies for optimal expenses (for the SBU - catering complex), differentiation (for the sports and tourist complex and the SBU - hotel complex) and the first movers (for the SBU "transport services"); at the functional level - strategies: minimizing costs, improving the quality of existing services (for the CBU - public catering complex), expanding the range of existing services by new ones (for the sports and tourist complex and the CBU hotel complex), active marketing (for all CBUs), significant changes in the organization of production (for the SBU catering complex), etc.

In 2012, Zakhar Berkut Ski Resort established and started implementing a synergistic strategic set, which suggested changing business strategies and functional levels of each SBU (hotel complex) and BU (all other business units of the resort) depending on certain conditions. For example, in the winter period for a sports and tourist complex it was expedient to use a strategy of optimal expenses, which allowed to increase revenues and the volume of services rendered by the hotel complex in the following way: the residents of the hotel for more than 5 days were provided with 1 day skiing for free, etc. In the summer, it was expedient to use a focus strategy for the sports and tourist complex, the essence of which was to focus on the services of the cableway, which attracted a significant number of visitors, who in turn increased the volume of the supplied services and incomes of the catering complex. The complex of catering in this case used a strategy of differentiation of sales points.

Having analyzed the data of the Table 1, we see that the income of business units was variable in different periods of the development of ski resort, namely, the growth of revenues for: BU "sports and tourist complex" in the 2nd period amounted to 4402.351 thsd. UAH, in III - 4297.078 thsd. UAH; BU "catering complex" - in the 2nd period 724.055 thsd. UAH, in III - 1634.25 thsd. UAH; BU "transport complex" - in the II quarter 672.37 thsd. UAH, in III -849.45 thsd.UAH; SBU "hotel complex" - II period 2984.16 thsd. UAH, in III - 5501.022 thsd. UAH. The uneven increase in revenues of the business units as a result of implementation of a synergistic strategic set is due to decrease in the values of certain indicators of some of them in favor of others. For example, a reduction in the price for services of the business unit "sports and tourist complex" in order to increase sales volumes, and, accordingly, the revenues of the SBU "hotel complex".

According to the data obtained, the list and structure of the SBU due to the interest of the revenues received in relation to other $\mathrm{BU}$, since the value of this indicator for the SBU should be the largest, which is explained by the peculiarities of the diversified enterprises operation considered in the paper [9] - the activity of the SBU is strengthened by all other BU.

The influence of the strategic and synergistic strategic sets on the market position of Zahar Berkut Ski Resort is reflected using the matrix of Boston Advisory Group (Fig. 1). Output data for construction is given in Table. 1 and 2.

The growth rate of the industry market is calculated as the ratio of the volume of services provided in the Skole district of the reporting period to the previous one.

The diameter of the circle of each business unit is determined by the ratio of the volume of its services to the total amount of services provided by Zakhar Berkut Ski Resort.

We estimate the relative share of the market as the ratio of the amount of services rendered by a certain business unit of Zahar Berkut Ski Resort to the volume of similar services of the main competitor. Business units with a high and low market share are divided according to the information obtained through surveys of tourists about the activities of competitors and observations of employees of the marketing department of Zakhar Berkut Ski Resort. 


\section{Source data for calculating the value of the indicator of growth rates of the industry market of tourist services in Skole District}

\begin{tabular}{|c|c|c|c|c|c|c|}
\hline \multirow{3}{*}{ Indicators } & \multicolumn{6}{|c|}{ Indicator value } \\
\hline & \multicolumn{2}{|c|}{$\begin{array}{l}\text { before strategy } \\
\text { implementation }\end{array}$} & \multicolumn{2}{|c|}{$\begin{array}{c}\text { having } \\
\text { implemented a } \\
\text { strategic set }\end{array}$} & \multicolumn{2}{|c|}{$\begin{array}{c}\text { having implemented a } \\
\text { synergistic strategic } \\
\text { set }\end{array}$} \\
\hline & 2006 & 2007 & 2009 & 2010 & 2011 & 2012 \\
\hline $\begin{array}{l}\text { The volume of services provided by hotels and } \\
\text { restaurants, thsd. UAH }\end{array}$ & 1435.7 & 1770.8 & 3861.7 & 7532.9 & 8956.6 & 9664.5 \\
\hline $\begin{array}{l}\text { The growth rate of the industry market of hotel } \\
\text { services and catering, } \%\end{array}$ & - & - & \multicolumn{2}{|c|}{95} & \multicolumn{2}{|c|}{8} \\
\hline $\begin{array}{l}\text { The volume of services in the culture and sports, } \\
\text { recreation and entertainment, thsd. UAH. }\end{array}$ & 40.7 & 28.3 & 17.7 & 217.3 & 264.3 & 321.2 \\
\hline $\begin{array}{l}\text { The growth rate of the sectoral leisure and } \\
\text { entertainment market, } \%\end{array}$ & - & - & \multicolumn{2}{|c|}{100} & \multicolumn{2}{|c|}{22} \\
\hline Total provided services, thsd. UAH & 1476.4 & 1799.1 & 3879.4 & 7750.2 & 9220.9 & 9985.7 \\
\hline $\begin{array}{l}\text { The growth rate of the industry market of } \\
\text { tourist services, } \%\end{array}$ & \multicolumn{2}{|c|}{22} & \multicolumn{2}{|c|}{99} & \multicolumn{2}{|c|}{9} \\
\hline $\begin{array}{l}\text { Volume of the provided transport services, } \\
\text { thsd. UAH }\end{array}$ & \multicolumn{2}{|c|}{-} & 8441.1 & 5240.0 & 5229.2 & 3717.2 \\
\hline $\begin{array}{l}\text { The growth rate of the industry market of } \\
\text { transport services, } \%\end{array}$ & \multicolumn{2}{|c|}{-} & \multicolumn{2}{|c|}{6.2} & \multicolumn{2}{|c|}{7.1} \\
\hline
\end{tabular}

Source: calculated by the author on the basis of [5]

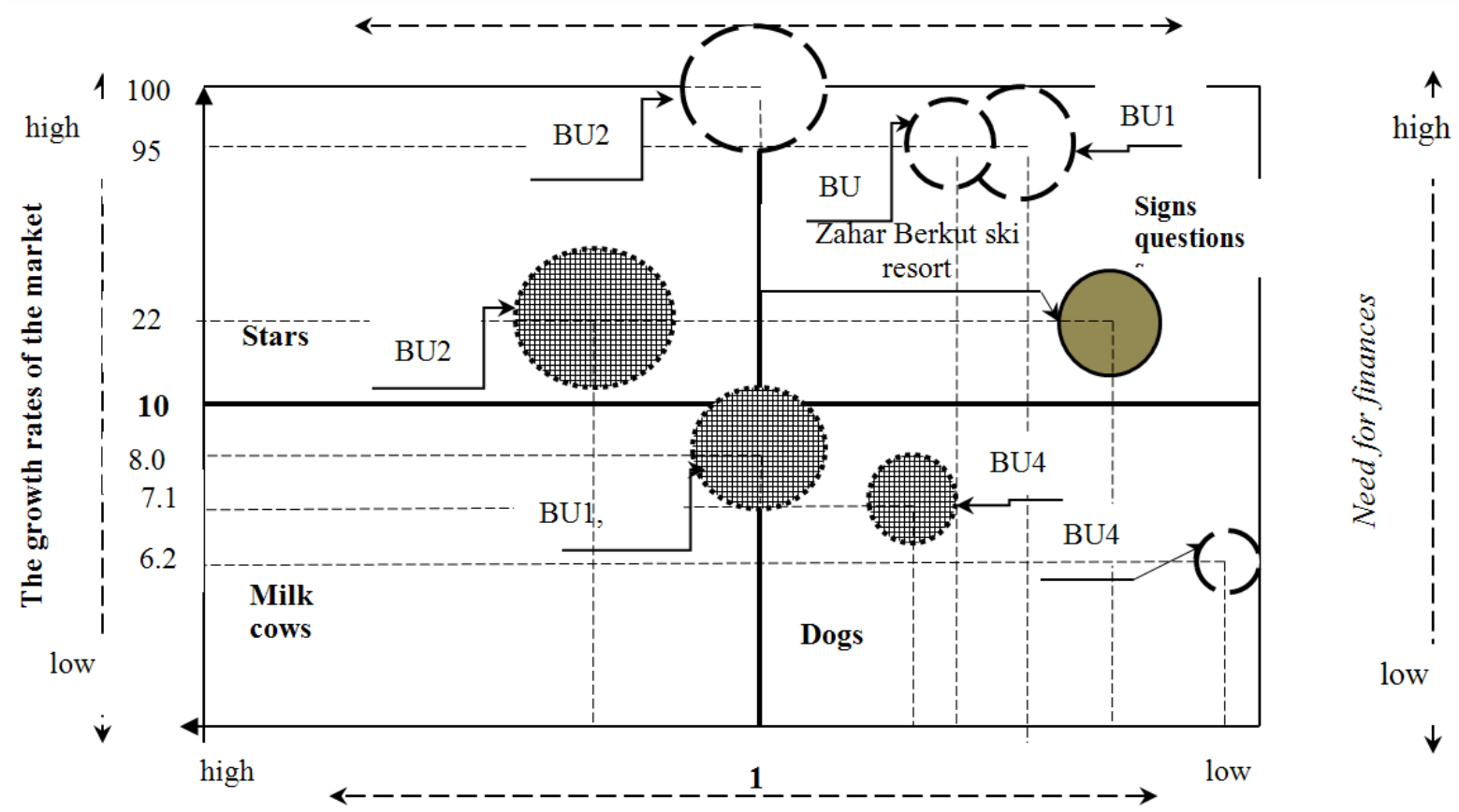

Relative market share

Zakhar Berkut Ski Resort at stage I of development;

() business units of the ski resort

of Zakhar Berkut ski resort, respectively, at the 2nd and 3rd stages

BU1 - Hotel complex; BU2 - Sports and tourist complex; BU3 - Catering complex; БU4 - Complex of transport services

Fig. 1. Positions of business units of Zakhar Berkut Ski Resort according to the BCG matrix Source: calculated and compiled by the author based on the collected data 
At the stage I of the development of Zakhar Berkut Ski Resort its main competitor was Trostian Ski Resort because the range, quality and price for the services of the hotel complex, as well as characteristics of the sports and tourist complexes, calculated using the method proposed in the work [10], were the most similar. However, the market position of Zahar Berkut Ski Resort in relation to Trostian Resort was extremely low, and accordingly the volume of services provided, due to the lack of sufficient information about Zahar Berkut Ski Resort, which has just come on the market.

The competitors of the business units of Zahar Berkut Ski Resort at the stage II of development were: the hotel complex - Pearl of the Carpathians Tourist Centre; sports and tourist complex - Trostian Ski Resort; the complex of catering and transport services was competing by private individuals who attracted considerable attention of consumers at low prices for goods and services, as well as the convenience and mobility of their provision (sales of products on portable flumes, etc.).

Over time, the attractiveness of ski resort facilitated the emergence of a large number of new, redesigned hotels, ski rental stores, attractive proposals from the instructors, and many more, near Zakhar Berkut Ski Resort. That caused the need to link the activities of Zakhar Berkut Ski Resort facilities with each other in such a way as to make them attractive at the right moments of time (development stage III). This became possible by the effect of synergy, and the possibility of forming this effect at all levels of management allowed to control the resort activities in general and, in particular, support the development and market positions of its business units at the appropriate level.

Thus, implementing a synergistic strategic set, there was a search for new opportunities for strengthening some business units by the others and fixing favorable conditions for each of them, which confirms the receipt of a significant profit level of the ski resort without increasing the costs the growth of profit in the period II mounted to 2123.085 thsd. UAH, in III - 6993.761 thsd. UAH, with the growth of costs in period II by 4488.338 thsd. UAH, and in III - 909.08 thsd. UAH.
It is clear that the effectiveness of a synergistic strategic set over a long period of time will depend on correctly selected strategies for each SBU and BU at each hierarchy level of strategies (corporate, business, functional, and operational).

\section{Conclusions and perspectives of further research}

The conducted research allows us to conclude that:

$f$ the efficiency of the operation of diversified enterprises is strengthened by the coordinated activity of all its business units, which, using a synergistic effect, is more efficient than the sum of the results of each business unit (BU) separately. This caused the need to study the possibility of forming a synergistic strategic set, which, unlike the strategic set, implies the functioning of a diversified company as the only mutually agreed entity by generating a synergistic effect at each level of management through the interactions between business, functional and operational strategies of all of its SBUs and BUs;

$f$ the implementation of the optimal synergistic strategic set of a diversified enterprise formed by establishing and choosing the most effective relationship (from the maximum possible) between the strategies ensured the maximum achievement of the strategic targets of Zahar Berkut Ski Resort: the conquest of new market positions; the achievement of long-term competitive advantages; the access to international markets, etc.

However, considering a diversified enterprise as consisting of SBU and BU, the question arises: "What strategies to consider at the given level, taking into account a different set of business units: one SBU, one BU; one SBU, several BUs; some SBUs, one BU, etc.)?" This issue requires a deeper and more detailed examination and describes the prospects for further research.

\section{References}

1. Bohatyriov, A. M., \& Stoliarska, K. M. (2001). Structure of Business Strategic Set. Strategy of Economic Growth of Ukraine, 28, 49-55 [in Ukrainian].

2. Business Plan of "Zakhar Berkut" Ski Resort Development (2004). Lviv: TzOV "OKTANT" [in Ukrainian]. 


\section{Kozyk, Kh. Zalutska, V. Zalutsky}

3. Van Horne, J. C., \& Wachowicz, J. M. (2003). Translation from English 2. Fundamentals of Financial Management. Moscov: Williams Publishing House [in Russian].

4. Holik, V. V. (2015). Strategic Set as Effective Tool for Promotion of Agricultural Enterprise Competitiveness. Current Problems of Economics, 2, 15-24 [in Ukrainian].

5. Main Statistical Office in Lviv Region (2009, 2012, 2013). Activity of Service Companies in Lviv Region (Statistical Yearbook). Retrieved from http://lv.ukrstat.gov.ua/ukr/publ/archive_publ.php?y=2 $013 \& y 1=12 \&$ ind_page $=$ archive [in Ukrainian] .

6. Dobronravova, I.S. (1990). Synergetics: Lateral Thinking Formation. Kyiv: Lybid [in Russian].

7. Dubrovyk, A. O., \& Kozak, L. V. (2008). Synergistic Effect in Business Management. Student Scholarly Notes of the National University of Ostroh Academy. "Economics" Series, 5, 98-104 [in Ukrainian].

8. Zakhar Berkut: Ski Resort and Hotel and Tourist Complex in Slavske - Ideal Winter Holidays in the Carpathians (2016). Retrieved from http://www.zaharberkut.net/ru ([in Ukrainian].

9. Kozyk, V.V., \& Zalutska, Kh .Ya. (2016). Peculiarities of Diversified Company Operation. "The scientific heritage" Journal, 3, 4-6 [in Ukrainian].

10. Melnyk, V. M., Shyiko, O. Ya., \& Solovii, Kh. Ya. (2006). Pricing Strategy in the System of Ski Resort Marketing Complex. Proceedings of the Sixth International Research-to-Practice Conference "Marketing and Logistics in Management System" [in Ukrainian].

11. Poplavska, Zh. (2001). Interaction Effect: Synergy in Economics. Bulletin of the National Academy of Sciences of Ukraine, 5, 39-42 [in Ukrainian].
12. Revenko, O. V. (2007). Peculiarities of Business Strategic Set Formation. Proceedings of the Third International Research-to-Practice Conference "Alliance of Sciences: from a Scientist to a Scientist". Retrieved from http://www. confcontact.com [in Ukrainian].

13. Svetlichnaya, T. I. (2007). Synergistic Strategy of Activity of Enterprises Belonging to Construction Sector of Ukraine. City Public Utilities: Scientific and Technical Collection, 77, 143-147 [in Russian].

14. Thompson, A. A., \& Strickland, A. J. (1998). Strategic Management. Art of Development and Implementation of Strategy: Textbook for Higher Education Institutions. Moscov: Banks and Exchange, UNITY [in Russian].

15. Haken, H. (1985). Synergetics: Instability Hierarchies of Self-Organizing Systems. Moscov: World [in Russian].

16. Shatska, Z. Ya., \& Matiushko, N. H. (2015). Peculiarities of Strategic Set Formation by Enterprises of Different Types. Global and National Economic Problems. Electronic Scientific Special Publication. Retrieved from http://globalnational.in.ua. - http://global-national.in.ua/issue4-2015/12-vipusk-4-berezen-2015-r/643-shatska-zya-matyushko-n-g-osoblivosti-formuvannyastrategichnogo-naboru-pidpriemstvami-riznikhtipiv [in Ukrainian].

17. Ansoff, H. I. (1987). Corporate Strategy, revised edition. Penguin Books;

18. Itami Hiroyuki, \& Roehl Thomas, H. (1987). Mobilizing Invisible Assets. Cambridge: Harvard University Press. 